\title{
Childbirth in the Adolescent Female at the General Hospital of Loandjili (Congo)
}

\author{
L. E. M. Eouani ${ }^{*}$, J. C. Mokoko², C. Itoua' ${ }^{2}$ L. H. Iloki² \\ ${ }^{1}$ Obstetrics and Gynaecology Department of the General Hospital of Loandjili, Pointe-Noire, Congo \\ ${ }^{2}$ Obstetrics and Gynaecology Department of the University Hospital Center of Brazzaville, Brazzaville, Congo \\ Email: *eouani@yahoo.fr
}

How to cite this paper: Eouani, L.E.M., Mokoko, J.C., Itoua, C. and Iloki, L.H. (2018) Childbirth in the Adolescent Female at the General Hospital of Loandjili (Congo). Open Journal of Obstetrics and Gynecology, 8, 1140-1146.

https://doi.org/10.4236/ojog.2018.812115

Received: July 8, 2018

Accepted: October 9, 2018

Published: October 12, 2018

Copyright (c) 2018 by authors and Scientific Research Publishing Inc. This work is licensed under the Creative Commons Attribution International License (CC BY 4.0).

http://creativecommons.org/licenses/by/4.0/

\begin{abstract}
Objective: To contribute to the knowledge of the characteristics of teenage birth. Patients and Methods: Retrospective, descriptive and comparative studies, from February $1^{\text {st }} 2014$ to April $31^{\text {st }} 2015$, carried out in the Obstetrics and Gynecology Department General Hospital of Loandjili. Included were births of less than 18 years of age at the end of a pregnancy of at least 22 weeks of amenorrhea on the one hand, and adults aged 18 and over, who had given birth at the same end of the pregnancy immediately after the teenager. Thus two populations consisted of 170 cases each. The parameters studied were: Sociodemographic, clinical and prognostic characteristics. Results: During this period, 4190 patients had given birth to 4341 births. Among them, 170 teenage girls are $4 \%$. The average age of teenagers in our study was 16.2 years with a 17 -year-age, versus 28.2 years for adults. The average parity was 1.19 . While in adults, multiparity was represented at $45.89 \%$ with an average parity of 3.19. The average number of prenatal consultations (ANC) was 2.89 for adolescent girls and 31.2\% had not been performed. By cons in adults, it was 4.23. These ANCs were started in teenage girls with an average of 22 weeks at the first ANC, while adults started on average at 18 weeks. The average delivery time was 38 weeks of amenorrhea for both populations. Thirty-four cases of premature newborns from adolescent mothers were observed, compared with 14 in adult mothers $(p<0.05)$. The delivery mode was low in $66 \%$ of adolescent girls versus $75 \%$ of adults. Indications for caesarean section in adolescents were represented by complications of arterial hypertension (38.59\%), followed by mechanical dystocia. While in adults, cervical dystocia and scar uteri were the most represented. During this study period, no maternal deaths were recorded among adolescent girls. Characteristics of the newborn: the condition of the newborn at birth was good according to the rating of Apgar among teenagers in $91 \%$, and in adults in $96.5 \%$ and, with a birth weight at teenage girls normal in $74 \%$ versus $88 \%$ in adults. Low birth weight and prematurity were reported with a statistically significant differ-
\end{abstract}


ence in adolescent girls.

\section{Keywords}

Adolescent, Childbirth, Caesarean Section, Newborn, Stillbirth

\section{Introduction}

The world health organisation defines the adolescent age as the group of youngsters aged from 10 to 19 years old [1] [2]. Among these adolescents, every year about 16 millions of young women from 15 to 19 years old give birth to a child.

The progress of the pregnancy in the adolescent female is often accompanied by the maternal and foetal mortality risk [2]. This risk is likely due to vascular injures characterized by an under developed arterial network and observed after the physiological immaturity in the adolescent mother. Pregnancy in a teenager is also risky for the unborn child. In low- and middle-income countries, births and deaths in the first week and first month of life are $50 \%$ higher in children born to mothers under the age of 20 than in children born to mothers aged 20 to 29 years. The risk is inversely proportional to the age of the mother.

The fertilization in young ages has a great risk of complication during the childbirth making it a public health problem. In Congo-Brazzaville, in 2004 a study concerned the adolescent pregnancy and childbirth in the capital town of Pointe-Noire on the one hand and in order to contribute to the knowledge of the characteristics of the adolescent childbirth on the characteristics of the adolescent childbirth; on the other, we have undertaken this work in comparing the adolescent parturition with other parturients.

\section{Methods}

A retrospective, descriptive and comparative study was undertaken from February $1^{\text {st }} 2014$ to April $31^{\text {st }}$ (15 months) in the obstetrics and gynecology department of the general hospital of Loandjili in Pointe-Noire. Adolescent parturients and others were concerned.

criteria for inclusions were women of less than 18 years old having given birth at end of a pregnancy of 22 weeks of amenorrhoea on the one hand and adults of 18 years old and more, who have given birth at the some pregnancy term.

One hundred and seventy cases of adolescent females were included in our study.

The cases of miscarriage of less than 22 weeks of amenorrhoea were excluded as well as the childbirths carried out of the department.

The enrollement of adults parturients concerned those of 18 years and mor met the same criteria for inclusion than the adolescent females, who have given birth as soon as they have been included.

Therefore, two populations of 170 cases each were formed. 
The parameters to be studied were: prevalence, age parity, the monitoring of the pregnancy, the child birth term, the mode of delivery, the maternal prognosis, the birth weight of the newborn and Apgar scores, the transfer to neonatology and the early neonatal and maternal death.

The Microsoft Excel software has allowed the registration of data and the statistical test applied was the average, the mode with chi-square of Pearson to compare the proportions. It was considered as significant when the $\mathrm{P}$ was inferior to 0.05 .

\section{Results}

During the period of study, 4190 patients have Given birth at the maternity department of the general hospital of Loandjili and delivered 4341 babies. Among them, 170 adolescents females represent $4 \%$.

The mean age of the adolescent females in our study is 16.2 years [extremes: 13 - 17 years], with a mode of 17 years versus a mean age of 28.2 years [extremes: 18 - 44 years] with a mode of 23 years in the adult women (Table 1).

Primiparous were $81.17 \%$ in the adolescent female and $18.82 \%$ in the pauciparous with of 1.19 where in the adults, multiparty was represented by $45.89 \%$ with a mean parity of 3.19 [extremes: 1 - 9].

The mean number of prenatal consultations was 2.89 [extremes: $0-8$ ] in the adolescent and $31.2 \%$ didn't do any and 58\% did. In the adults, the number prenatal consultation was 4.23 [extremes: 0 - 11]. The majority of prenatal consultations started late in the adolescent with a mean term of 22 weeks at the first prenatal consultations whereas the adult started their prenatal consultation at a mean of 18 weeks. The term of the childbirth was at a mean of 38 weeks of amenorrhea in the adolescents as well as in the adults (Table 2).

34 cases of premature newborns of adolescent mothers have been observed versus 14 in the adult mothers $(\mathrm{p}<0.05)$.

The mode of delivery was vaginal in the $66 \%$ adolescent versus $75 \%$ adults ( $\mathrm{p}$ $<0.05)$.

The indications of caesarean in the adolescent were represented by the complication of hypertension (38.9\%) followed by the obstructed labour. Whereas in the adults, cervical dystocia in the scarred uterus was the most represented as reported in Table 3.

During the period of study no maternal death was recorded in the adolescents.

The characteristics of the newborn represented by Table 4, thus the state of the newborn at birth was good according to Apgar scores in the adolescents in $91 \%$ and, with a weight at birth normal in the adolescents in $74 \%$ versus $88 \%$ in the adults. The small weights at birth with the prematurity where reported with a signification statistical difference.

\section{Discussion}

Our frequency of childbirth is near to that found in the same country who reported 
Table 1. Sociodemographic characteristics.

\begin{tabular}{ccc}
\hline & Adolescents & Adults \\
\cline { 2 - 3 } & Extreme means & Extreme means \\
\hline Age & $16.2[13-17$ years $]$ & $28[18-44$ years $]$ \\
Parity & $1.19[1-2]$ & $3.19[1-9]$ \\
Nbre of prenatal consultation & $2.89[0-8]$ & $4.23[0-11]$ \\
Term of the onset of prenatal consultation & 22 weeks & 18 weeks \\
\hline
\end{tabular}

Table 2. Characteristics of childbirth.

\begin{tabular}{lccc}
\hline & adolescents & Adults & $\mathrm{P}$ \\
\cline { 2 - 4 } & $\mathrm{n} \%$ & $\mathrm{n} \%$ & \\
\hline Term of childbirth & & & $<0.05$ \\
Before term & $34-20$ & $14-8$ & $>0.05$ \\
Term & $124-73$ & $142-84$ & $>0.05$ \\
After term & $11-7$ & $14-8$ & \\
Way of childbirth & & & $>0.05$ \\
Vaginal delivery & $113-66$ & $127-75$ & \\
Abdominal delivery & $57-34$ & $45-25$ & \\
Instrumental extension & 11 & 6 & \\
Perineal tearing & 15 & 5 & \\
Episiotomy & 20 & 11 & \\
\hline
\end{tabular}

Table 3. Indication of the cesarean

\begin{tabular}{ccccc}
\hline & \multicolumn{2}{c}{ Adolescents } & Adults & $\mathrm{P}$ \\
\cline { 2 - 4 } & $\mathrm{n}$ & $\%$ & $\mathrm{n}$ & $\%$ \\
\hline Scaring uterus & 1 & 1.71 & 9 & 20 \\
Cervical dystocia & 3 & 5.26 & 9 & 10 \\
Complication of HBP & 17 & 38.59 & 4 & 8.88 \\
Obstructed labour & 17 & 29.82 & 6 & 13.33 \\
Fœtal suffering & 10 & 17.52 & 8 & 17.11 \\
Seage & 2 & 3.50 & 5 & 8.8 \\
Preavia placenta & - & - & 4 & - \\
Pre-rupture & 2 & 3.50 & - & 111 \\
Total & 57 & $100 \%$ & 45 & \\
\hline
\end{tabular}

Table 4. Characteristics of newborns.

\begin{tabular}{|c|c|c|c|c|c|}
\hline & \multicolumn{2}{|c|}{ Adolescents } & \multicolumn{2}{|c|}{ Adults } & \multirow{2}{*}{$\mathrm{P}$} \\
\hline & $\mathrm{n}$ & $\%$ & $\mathrm{n}$ & $\%$ & \\
\hline \multicolumn{6}{|l|}{ Bath weight } \\
\hline $1400-2499$ & 42 & 24.8 & 7 & 10.6 & 0.05 \\
\hline $2500-3999$ & 126 & 74 & 151 & 88.2 & 0.05 \\
\hline $4000-4900$ & 2 & 1.2 & 2 & 1.2 & 0.05 \\
\hline \multicolumn{6}{|l|}{ Apgar scores } \\
\hline 0 & 5 & 3 & 1 & 0.5 & 0.05 \\
\hline $1-3$ & 2 & 1.2 & 0 & 0 & 0.05 \\
\hline $4-7$ & 9 & 5 & 5 & 3 & 0.05 \\
\hline $8-10$ & 154 & 91 & 164 & 96.5 & 0.05 \\
\hline Neonatal transfer & 6 & 3.53 & 3 & 1.77 & \\
\hline
\end{tabular}


$5.3 \%$ in 2014 [3]. Whereas the superior rates have been found in Niger at $10.5 \%$ [4], in TCHAD at $18 \%$ by FOUMSON [5]. However, it is inferior to that reported in TOGO who have found at 2.9\% [6]. Anyway, the who reported that the children born of adolescent mother's world and 95\% of births in the developing countries [5]. Mabiala [7] in Congo reported in 2018 that 59.4\% of adolescents females benefited of family planning services for the contraception on the one hand, and $64.7 \%$ have already practised a voluntary termination of a pregnancy. The same reasons matter to explain the tendency to low frequencies observed in our series.

Certain authors accuse in many ways the cultural ethnics, religion and environmental context explained by illiteracy, the early marriages, the weakness of the prevalence of contraception, the prohibition of the voluntary termination of a pregnancy, the insufficiency of service, of health for youngs and in addition, the failure of national familial planning programmes [4] [8].

In Congo, the mean age of the first sexual intercourse was 14 years old in 2006 [7] which consequently would be responsible of the observed early pregnancies. The earliness of sexual intercourse as a worldwide phenomenon reported by many authors [6] [9]. However on other continents namely on Asia, in Latin America and Caribbean countries the age of the beginning of the sexual activity is around 20 years [6]. According to lane and call, it was recommended that the women delay the in first pregnancy until 18 years [9]. The adolescent females have had pregnancy less monitored than adult women and the beginning has been late. This point has been made by most of the authors [10]. Therefore they observe that the quality of the monitoring and the beginning of prenatal consultation depended on the age of debut the latter. The younger the adolescent, the later the monitoring of the pregnancy and worse was the quality [8] [10].

In our series, the end of the pregnancy was done in most cases by vaginal delivery.

The rate of childbirth by delivery of adolescent females have been inferior to that of the adult mothers, in spite of the immaturity of the pelvis considered a favouring factor of obstructed labour. Therefore, the cesarean has been practised of the time in the adolescent female than in the pregnant adults with obstructed labour as the most found indication. Traore [11] in Mali reported a prevalence of $37.5 \%$ of dystocic childbirth in the adolescent female.

Many authors have mentioned the risk of cesarean by obstructed labour in the adolescent female, related to the immaturity of the pelvis [3] [8].

In Niamey, the authors have made the cesarean compulsory in the adolescent female of 15 years and less [4]. They justify this indication of cesarean by the prevention of maternal deaths of certain serious maternal morbidities in this age group.

Foumsou [5] in Tchad find a maternal mortality of $2.8 \%$ which would be related partly to the lack of blood products. The hemorrhage was in $80 \%$ of the case of death. In our study the recommendation of the National Observatory of 
Maternal Death in Congo issued from the evaluation of maternal deaths in our hospital center have permitted the implementation of a deposit of the blood product of the hospital in the department. This contributed to reduce the onset of maternal deaths in our hospital as a whole.

The hemorrhage was the first cause of maternal deaths. Our result did not notice any significant difference in the two groups in the newborns with Apgar scores inferior to 7. This correspond to these reported by Kaka [2] in DRC (Democratic Republic of Congo). However they differ from these observed in the series of ILOKI and coll [3] in Congo and that of Soula it call [12] In French Guyana.

The premature childbirth in the adolescent female is significantly superior to the central group. As testify many authors [2] [4] [6]. Guiot [13] demonstrate that the risk of the prematurity decreases in the pregnant adolescent well monitor.

According to the literature data [5] [10] [14], the low weight at birth has marked proportion of adolescent female our series. Hoque it call [14], et al. Genest [10] underline that the more important premature rare in the adolescent originate from many factor and must take into account namely the socioeconomic characteristic.

\section{Conclusion}

Like other authors, our study notes that pregnancy during adolescence remains a risky situation in our countries. The clear improvement in the maternal and fetal prognosis requires preventive measures concerning access to reproductive health care for these young mothers, and improving the quality of prenatal follow-up offered to them. Actions need to be taken to improve adolescent girls' access to family planning services and raise awareness about the dangers of poor prenatal care.

\section{Conflicts of Interest}

The authors declare no conflicts of interest regarding the publication of this paper.

\section{References}

[1] OMS (2002) Services de santé adaptés aux adolescents. Un programme pour le changement, OMS, Genève, 48.

[2] Kaka, J.C. and Kabakele, A. (2014) Issues d'accouchement chez les adolescentes au Centre Mère-Enfant de Bumbu à Kinshasa (République Démocratique du Congo). Médecine d'Afrique noire électronique, 61, 289-296.

[3] Iloki, L.H., Koubaka, R., Itoua, C. and Mbemba Moutounou, G.M. (2004) Grossesse et accouchement chez l'adolescente au Congo. A propos de 276 cas au CHU de Brazzaville. Journal de Gynécologie Obstétrique et Biologie de la Reproduction, 33, 37-42. https://doi.org/10.1016/S0368-2315(04)96310-7

[4] Nayama, M., Dan Malan Bouzou, R., Nayoussa, M. Hamani, R., Moustapha, F., 
Garba, M., Idi, N., Kamaye, M. and Djibrill, B. (2007) Prise en charge de l'accouchement chez les adolescentes au niveau de la maternité Issaka Gazobi de Niamey Etude rétrospective à propos de 976 observations sur 3 ans. Médecine d' Afrique noire électronique, 54, 414-418.

[5] Foumsou, L., Gabkika, B.M., Saleh, A. and Memadji, M. (2004) Les complications obstétricales chez les adolescentes à la maternité de l'hôpital général de référence nationale (HGRN) de N’Djamena. Médecine d'Afrique noire électronique, 61, 442-447.

[6] Aboubakari, A.S., Djadou, K.E., Saka, B., Tchagbele, O.B., Agbere, A.D., Atakouma, D.Y., Bakonde, B., Gbadoe, A. and Tatagan-Agbi, K. (2013) Accouchement chez l'adolescent de moins de 17 ans à l'Hôpital de Tsevie (Togo): Précocité des premiers rapports sexuels en Afrique subsaharienne. Journal de la SAGO, 14, 17-21.

[7] Mabiala Babela, J.R., Massamba, A., Bantsimba, T. and Senga, P. (2008) La sexualité de l'adolescent à Brazzaville, Congo. Journal de Gynécologie Obstétrique et Biologie de la Reproduction, 37, 510-515. https://doi.org/10.1016/j.jgyn.2007.11.033

[8] Nguembi, E., Yanza, M.C., Sepou, A., Poussoumandji-Guezza, M., Nali, M.N. and Zohoun, T. (2005) La grossesse chez les adolescentes dans la ville de Bouar (Centrafrique). Médecine d Afrique noire électronique, 52, 681-685.

[9] Lane, C., Joof, Y.M., Hassan, A.A. and Pryor, S. (2012) Pomoting Healthy Timing and Spacing of Pregnancy with Young Married Women in Nortthen Nigeria: A Short Report. African Journal of Reproductive Health, 16, 263-269.

[10] Genest, L., Decroix, H., Rotten, D. and Simmat-Durand, L. (2014) Maternité précoce: Profils sociodémographiques de 220 mères adolescentes en Seine-Saint-Denis. Journal de Gynécologie Obstétrique et Biologie de la Reproduction, 351-360. https://doi.org/10.1016/j.jgyn.2013.03.009

[11] Traore, B., Thera, A.T., Kokaina, C., Beye, S.A., Mounkoro, N., Teguete, I., Traore, Y. and Dolo, A. (2010) Les accouchements dystociques au Centre Hospitalier Régional de Ségou au Mali-A propos de 240 cas. Médecine d Afrique noire électronique, 57, 161-165.

[12] Soula, O., Carles, G., Largeaud, M., Ei Guindi, W. and Montoya, Y. (2006) Grossesse et accouchement chez les adolescentes de moins de 15 ans. Etude de 181 cas en Guyane française. Journal de Gynécologie Obstétrique et Biologie de la Reproduction, 35, 53-61. https://doi.org/10.1016/S0368-2315(06)76372-4

[13] Guiot, O., Foucan, T., Janky, E. and Kadhel, P. (2013) Grossesses évolutives chez les mineures en Guadeloupe: nouvel état des lieux. Journal de Gynécologie Obstétrique et Biologie de la Reproduction, 42, 372-382. https://doi.org/10.1016/j.jgyn.2013.02.007

[14] Hoque, M. and Hoque, S. (2010) Comparison of Perinatal and Obstetrics Outcomes among Early Adolescents, Late Adolescents and Adult Pregnant Women from Rural South Africa. African Journal of Primary Health Care \& Family Medicine, 2, 1-5. https://doi.org/10.4102/phcfm.v2i1.171 